\title{
MEASURING CORTICAL ACTIVITY DURING AUDITORY PROCESSING WITH FUNCTIONAL NEAR-INFRARED SPECTROSCOPY \\ Contributions:
}

A Study design/planning B Data collection/entry C Data analysis/statistics D Data interpretation

E Preparation of manuscript F Literature analysis/search $\mathrm{F}$ Literature analysis/s
$\mathrm{G}$ Funds collection

\author{
Luuk P. H. van de Rijt ${ }^{1,2 D E F}$, Marc M. van Wanrooij ${ }^{2 E}$, Ad. F. M. Snik ${ }^{1 E}$, \\ Emmanuel A. M. Mylanus ${ }^{1 \mathrm{E}}$, A. John van Opstal ${ }^{2 \mathrm{E}}$, Anja Roye ${ }^{2 \mathrm{E}}$
}

Acknowledgments. Supported by Radboud University (MMVW), RadboudUmc (LPHR, EAMM), EU FP7-PEOPLE-2013 grant iCare (nr. 607139; AR), and EU H2020 ERC 2016 Adv. grant ORIENT (nr. 693400; AJVO; AFMS)

\footnotetext{
${ }^{1}$ Department of Otorhinolaryngology, Donders Institute for Brain, Cognition, and Behaviour, Radboud University Medical Center, Nijmegen, The Netherlands

2 Department of Biophysics, Donders Institute for Brain, Cognition, and Behaviour, Radboud University, Nijmegen, The Netherlands
}

Corresponding author: Department of Otorhinolaryngology, Donders Institute for Brain, Cognition, and Behaviour, Radboud University Nijmegen, Heyendaalseweg 135, 6525 AJ Nijmegen, The Netherlands, Telephone: +31 243614 238, Email: luuk.vanderijt@radboudumc.nl

\begin{abstract}
Functional near-infrared spectroscopy (fNIRS) is an optical, non-invasive neuroimaging technique that investigates human brain activity by calculating concentrations of oxy- and deoxyhemoglobin. The aim of this publication is to review the current state of the art as to how fNIRS has been used to study auditory function. We address temporal and spatial characteristics of the hemodynamic response to auditory stimulation as well as experimental factors that affect fNIRS data such as acoustic and stimulus-driven effects. The rising importance that fNIRS is generating in auditory neuroscience underlines the strong potential of the technology, and it seems likely that fNIRS will become a useful clinical tool. Keywords: near-infrared spectroscopy (NIRS) • functional near-infrared spectroscopy (fNIRS) • brain activity • auditory cortex.
\end{abstract}

\section{MEDICIÓN DE LA ACTIVIDAD CORTICAL DURANTE EL PROCESAMIENTO AUDITIVO CON ESPECTROSCOPIA FUNCIONAL INFRARROJA CERCANO}

Resumen

La espectroscopia funcional de infrarrojo cercano (fNIRS) es una técnica óptica de neuroimagen no invasiva que investiga la actividad cerebral humana calculando las concentraciones de la oxihemoglobina y la desoxihemoglobina. El objetivo de esta publicación es revisar el estado actual de esta técnica y ver como la fNIRS se ha usado para estudiar la capacidad de la audición. Abordamos las características temporales y espaciales de la respuesta hemodinámica a la estimulación auditiva, así como los factores experimentales que afectan los datos fNIRS, como los efectos acústicos y los impulsados por estímulos. La creciente importancia que fNIRS está adquiriendo en la neurociencia auditiva subraya el gran potencial de la tecnología, y parece probable que fNIRS se convierta en una herramienta clínica útil.

Palabras clave: espectroscopia de infrarrojo cercano (NIRS) • espectroscopia de infrarrojo cercano funcional (fNIRS) • actividad cerebral, corteza auditiva.

\section{ИЗМЕРЕНИЕ АКТИВНОСТИ КОРЫ ГОЛОВНОГО МОЗГА ВО ВРЕМЯ ОБРАБОТКИ ЗВУКА ПРИ ИСПОЛЬЗОВАНИИ ФУНКЦИОНАЛЬНОЙ БЛИЖНЕЙ ИНФРАКРАСНОЙ СПЕКТРОСКОПИИ}

\begin{abstract}
Аннотация
Функциональная ближняя инфракрасная спектроскопия (fNIRS) представляет собой оптическую, неинвазивную методику нейровизуализации, которая исследует деятельность человеческого мозга путем расчёта концентрации окси- и дезоксигемоглобина. Целью этой публикации является анализ актуальных знаний на тему того, каким способом использовать функциональную ближнюю инфракрасную спектроскопию (fNIRS) для проверки функционирования слуховой системы. Мы ссылаемся на временную и пространственную характеристику гемодинамического ответа на стимуляцию слуха, а также на экспериментальные факторы, которые влияют на данные функциональной ближней инфракрасной спектроскопии (fNIRS), такие как акустические и стимулирующие эффекты. Растущее значение
\end{abstract}


функциональной ближней инфракрасной спектроскопии (fNIRS) в слуховой неврологии подчеркивает сильный потенциал этой технологии, и вероятно функциональная ближняя инфракрасная спектроскопия (fNIRS) станет полезным клиническим инструментом.

Ключевые слова: спектроскопия в ближней инфракрасной области (NIRS) • функциональная ближняя инфракрасная спектроскопия (fNIRS) • активность мозга • слуховая кора.

\title{
POMIAR AKTYWNOŚCI KOROWEJ PODCZAS PRZETWARZANIA SŁUCHOWEGO PRZY UŻYCIU FUNKCJONALNEJ SPEKTROSKOPII W BLISKIEJ PODCZERWIENI
}

\begin{abstract}
Streszczenie
Funkcjonalna spektroskopia w bliskiej podczerwieni (fNIRS) jest optyczną, nieinwazyjną techniką neuroobrazowania, która bada aktywność ludzkiego mózgu poprzez obliczanie stężeń oksy- i dezoksyhemoglobiny. Celem tej publikacji jest dokonanie przeglądu aktualnego stanu wiedzy na temat tego, w jaki sposób zastosowano fNIRS do badania funkcjonowania układu słuchowego. Odnosimy się do czasowej i przestrzennej charakterystyki odpowiedzi hemodynamicznej na stymulację słuchu, a także do czynników eksperymentalnych, które wpływają na dane fNIRS, takie jak efekty akustyczne i wzbudzone bodźcami. Rosnące znaczenie, jakie fNIRS zdobywa w neuronauce słuchowej, podkreśla silny potencjał tej technologii i wydaje się prawdopodobne, że fNIRS stanie się przydatnym narzędziem klinicznym.
\end{abstract}

Słowa kluczowe: spektroskopia w bliskiej podczerwieni (NIRS) • funkcjonalna spektroskopia w bliskiej podczerwieni (fNIRS) • aktywność mózgu • kora słuchowa.

\section{Background}

Functional near-infrared spectroscopy (fNIRS) is an optical neuroimaging technique that assesses cerebral activity based on hemodynamics, which is associated with changes in the transmission of low power near-infrared light directed through the scalp and skull intothe brain (1). A variety of alternative terms have been used for the near-infrared spectroscopy (NIRS) technique, such as diffuse optical topography or tomography (DOT), diffuse optical imaging (DOI), and near infrared imaging (NIRI), although the underlying concept and physiological underpinnings remain similar (for detailed general reviews see e.g. (2-4)).

Brain activity leads to an increase in oxygen consumption, which is accompanied by an increase in cerebral blood flow due to neurovascular coupling (5). This induces a change in the local oxygenated $\left(\mathrm{HbO}_{2}\right)$ and deoxygenated hemoglobin (HbR) concentrations. Given the different absorption coefficients of specific wavelengths of near-infrared light (600-900 nm) by $\mathrm{HbO}_{2}$ and $\mathrm{HbR}$, changes in the concentration of each of these chromophores can be extracted by measuring changes in the amount of light transmitted over time (6). Due to the relatively low absorbance of near-infrared wavelengths by biological tissue, the cerebral cortex can thus be imaged. Specific parameters of the hemodynamic response observed with fNIRS hence reflect the spatial and temporal characteristics of changes in $\mathrm{HbO}_{2}$ and $\mathrm{HbR}$, which may be manipulated by experimental paradigms and sensory stimuli (see below).

FNIRS is perfectly suited to the study of auditory processing in human subjects of all ages $(7,8)$, since fNIRS is a non-invasive and silent brain-imaging technique, as opposed to PET (9) and fMRI (10). Further, the technique does not interfere with electromagnetic bionic devices such as cochlear implants $(8,11)$. Since the technique is silent (as opposed to fMRI), subjects can be seated in a normal (laboratory) environment, in which they can readily perform real-world psychophysical tasks, and the technique can be easily coupled with simultaneous EEG recordings. Because of these advantages, an increasing number of researchers are seeing the potential of fNIRS in auditory research for both normal-hearing and hearing-impaired listeners (12).

The objective of this article is to review the current state of the art as to how fNIRS has been employed to evaluate auditory function, such as in speech, non-speech processing, and auditory attention in adults. In general, obtaining an optimal and stable setup and design for adequate hypothesis testing with fNIRS still remains a challenge. To test hypotheses of auditory processing requires a thorough understanding of the cortical hemodynamic response to acoustic stimuli, and how this response may be modulated by stimulus presentation rate, duration, sound level, and attention. Identifying the experimental factors that might affect the hemodynamic response is paramount for acquiring reliable and valid data.

The specific objectives of this paper are as follows: (i) to introduce the temporal and spatial characteristics of hemodynamic changes to auditory stimulation in general; (ii) to identify experimental factors that affect hemodynamic changes measured with fNIRS; (iii) to obtain insights into common experimental paradigms; and finally (iv) to summarize the contributions fNIRS has made so far to the study of auditory functioning.

\section{Temporal and spatial characteristics of the hemo- dynamic response}

\section{Temporal characteristics of the hemodynamic response}

FNIRS should be regarded as an indirect measure of neural activity, as it only measures vascular changes. The hemodynamic response to cortical neural activity relies on the fact that neuronal firing and the associated vascular response are strongly coupled (cf. neurovascular coupling; for a review see (13)).

Although crucial to this neuroimaging method, the mechanisms of neurovascular coupling are still not fully understood. It is clear that active neuronal tissue consumes energy for which the required inflow of oxygen and glucose will be accompanied by a local increase of cerebral blood flow, resulting in a local excess of oxygen in that particular 


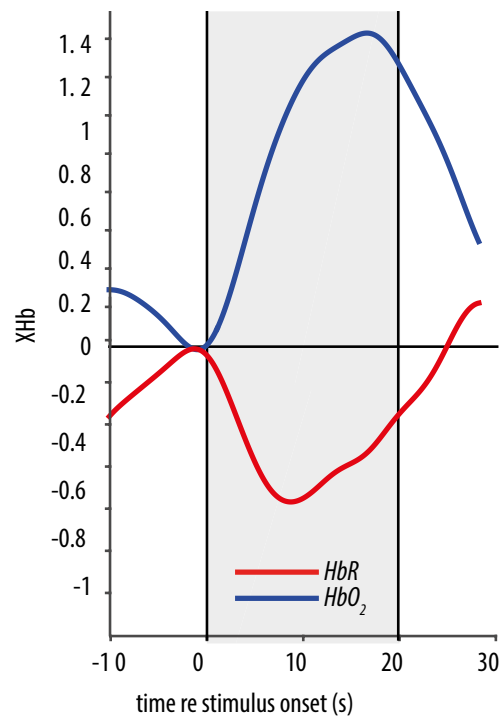

area. This local increase of cerebral blood flow is associated with an increase of $\mathrm{HbO}_{2}$ and a decrease of $\mathrm{HbR}$ (see Figure 1 for an example). This characteristic behaviour is usually described as the hemodynamic response function (HRF), and is well characterized for adults $(14,15)$. The characteristic HRF is related to the blood oxygenation level-dependent (BOLD) response that is also measured with fMRI $(11,16)$, although the BOLD signal proper is assumed to reflect changes in HbR only (for a review on hemodynamic changes measured with fMRI see (17)).

In general, the onset of the hemodynamic response lags the much faster electrical neural response to sensory stimulation by about $2 \mathrm{~s}$. The changes in $\mathrm{HbO}_{2}$ and $\mathrm{HbR}$ start with a steep increase, which rises to a plateau about 6-10 s after stimulus onset. The recovery time for the $\mathrm{HbO}_{2}$ and $\mathrm{HbR}$ responses to return to baseline is only infrequently reported (18), and is about 9-10 s (14). While both hemoglobin species $\left(\mathrm{HbO}_{2}\right.$ and $\left.\mathrm{HbR}\right)$ are well correlated regarding their temporal characteristics and shape during the steady state of the stimulus, sometimes an initial overshoot and a poststimulus undershoot may be observed for both chromophores (19). These are assumed to be a specific characteristic of neurovascular coupling (20).

Besides the general characteristics of the hemodynamic response, an important question is to what degree it is linearly related to the underlying neural activity, and hence whether it scales with stimulus input strength and

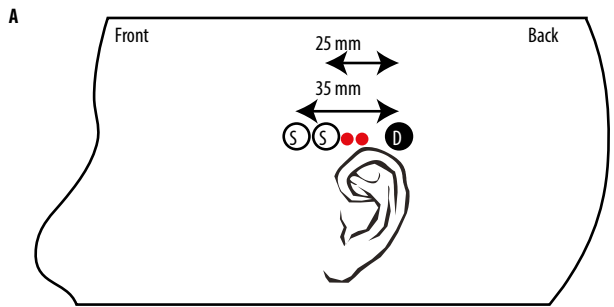

obeys the superposition principle to multiple stimuli (on model linearity see e.g. (21)). For example, Soltysik et al. (23) reported that the auditory response obeys linearity for stimuli of a relatively long duration, but reveals nonlinear properties for short-duration stimuli $(<10 \mathrm{~s})$. It has also been suggested that responses become non-linear at higher stimulus presentation rates $(22,24,25)$. Although, general aspects of hemodynamics might be partly responsible for non-linear response behaviour (e.g. saturation), another contribution could be due to the underlying neuronal responses, which can be enhanced by changes in the acoustic input, but will be suppressed for ongoing, tonic inputs (e.g., due to neural adaptation; for a review see (26)).

\section{Spatial information obtained with NIRS}

Figure 2 shows the probe template for two optical sources (S) and one photodetector (D) using source-detector distances of 25 and $35 \mathrm{~mm}$, respectively (termed reference or shallow, and deep channel, respectively) (27). In this figure, the detector records the transmitted light coming from two sources, and each source-detector combination is defined as a channel. The sources transmit their light at unique frequencies in order to distinguish, using a lock-in amplifier, which source transmitted the light.

The first fNIRS measurements were carried out at only one or a few locations on the skull $(11,28)$. Since

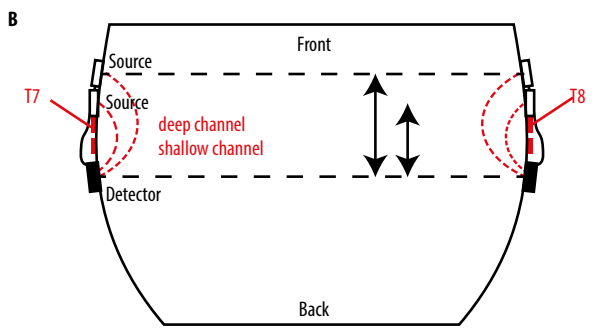

Figure 2. Positioning of the optodes. A) Layout of optical sources (open circles) and photodetectors (filled circles) on the left hemisphere; B) schematic top view of probe layout. The estimated T7 and T8 positions of a 10/20 system are also indicated, as these are the supposed superficial centers of the deep and shallow channels (red filled circles). Red dotted lines denote the average path from source to detector, estimated to be part of an ellipsoid with a penetration depth of approximately 2-3 cm. Image adapted from Van de Rijt et al., 2016 (27). 
stimulus-evoked brain activity occurs at restricted regions in the brain, one might miss the activation of interest when measuring just one brain area. Hence, a major step was to utilize multi-channel fNIRS systems which allow the possibility of measuring cortical hemodynamics from several cortical locations and construct topographic activity maps (29-32). Recently, researchers have developed a 140-channel fNIRS system to enhance local sensitivity - measured with several source-detector distances over overlapping regions to enable three-dimensional image reconstructions $(33,34)$. The method resembles the topographic mapping techniques familiar with $\mathrm{PMRI}$ measurements.

b. Multi-channel measurements can certainly be regarded as an important development towards establishing fNIRS as a neuroimaging method that allows neuronal activity mapping over wide or distributed brain areas. However, unlike MRI, NIRS does not allow structural imaging of the brain, and so several refinements have to be made to overcome this limitation and allow reliable measurements and valid conclusions: 1) Positioning should be accurate and reproducible to guarantee that recordings are taken from the same location; 2) Valid inferences on targeted brain areas recorded with different channels should be possible. 3) One should remove systemic noise from cortical brain activity.

\section{Reliable positioning and valid inferences about un- derlying sources}

Most researchers align the fNIRS channels (area between source and detector) with selected electrode positions of the well-established international 10-20 system (35-37). Although this procedure secures reliable positioning in general, conclusions about underlying cortical regions can only be drawn in a probabilistic manner (38). Obviously, some variance of the data will be attributable to the variability of defining the positions based on the 10-20 system across subjects and sessions (39).

Another option to enhance reliability and validity, and to avoid the variance induced by the $10-20$ system, is to align recorded optode locations with anatomical positions of the channels by using magnetic resonance (MR) structural images. Investigators have used markers (e.g. alfacalcidol beads/ vitamin D or E) to determine which cortical structures were measured by fNIRS in the studied participant $(40,41)$. This procedure ensures that the data were obtained from the region of interest, and therefore 'auditory channels' can be defined a priori $(41,42)$.

A third way to improve reliability is by demonstrating spatial similarity in functional data obtained with alternative neuroimaging methods. Some research groups have used both fNIRS and fMRI to compare cortical measurements of speech-evoked activity (11). Others have used magneto-encephalography (MEG) and application of a $1000 \mathrm{~Hz}$ tone to determine the active region of the auditory cortex and so model the electric source of the $\mathrm{N} 1 \mathrm{~m}$ response (28).

Finally, implementing a localizer task into the experimental protocol of the fNIRS recordings itself, besides the experimental contrast, can also be a valuable method to determine regions of interest. For auditory experiments this could be a standard auditory stimulus (tones or noise), or the average response to all experimental stimuli used, which is then compared to a silent baseline period. Channels that exhibit maximal hemodynamic changes may then be followed up in further steps of the analysis (43). Alternatively, Kennan et al. [45] implemented a motor task (i.e. finger-tapping) within an auditory oddball task to localize the relative position of activation in primary motor cortex. These different approaches may contribute to improved inferences about target areas within and between studies.

\section{Distinguishing physiological noise from cortical brain signals}

When looking at the raw fNIRS signals recorded from NIRS channels, which are supposed to target certain brain areas, systemic or physiological noise often pollutes the hemodynamic responses of interest. These physiological sources of noise, such as heart beat, respiration, or Mayer waves (44) may hide experimental effects which are usually of much smaller amplitude, and it may require sophisticated methods to identify the latter. Using a 'reference channel' offers a possible way to increase the reliability of estimating the hemodynamic response from fNIRS signals $(27,44,45)$. A reference channel is characterized by a short source-detector distance (range of 1-2 cm, see Figure 2), and makes use of the direct relation between source-detector distance and depth reached by photons in tissues underlying the scalp (46-48). Due to the short distance of the reference channel, it is likely to reflect hemodynamic activity that is taking place within superficial tissues rather than stimulus-evoked brain activity. Signals derived from the reference channel seem to be perfectly suited for subtraction of physiological noise from the measured NIRS signal (i.e. reference channel subtraction (RCS)), and has been demonstrated to facilitate the estimation of evoked cortical hemodynamic responses (49-51) (Figure 2). In Figure 3 an example is shown of how, at the single-subject level, RCS affects the average response during auditory

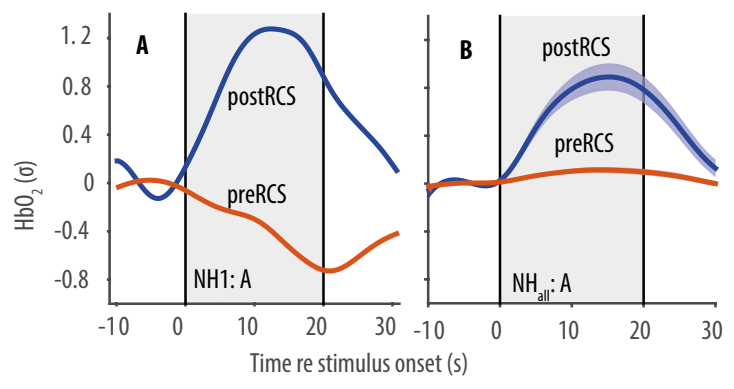

Figure 3. Reference channel subtraction. The red lines depict pre-reference-channel subtraction and the blue lines depict post-reference-channel subtraction. Grey patches indicate auditory stimulus presentation. Stimulus presentation was 20 s. A) Averaged normalized $\mathrm{HbO}_{2}$ data for 12 auditory stimuli of a normalhearing subject (NH1); B) the same for a normal-hearing cohort $(n=33)$. Image adapted from Van de Rijt et al., 2016 (27). 
stimulation. In general, it improves the signal response (Figure 3B; for further explanation see (27)).

\section{Choosing the most appropriate experimental paradigm}

Besides potential methodological difficulties in placing the optodes and removing physiological noise, a further important consideration for optimising data quality is the experimental paradigm used in an fNIRS study. With a few exceptions $(37,52)$, the majority of NIRS studies employ a block design. In this approach, the different experimental conditions are presented separately within relatively long blocks (4-30 s) of stimulation. Within each block, tokens of the same stimulus type are presented repetitively, or in an ongoing manner. Stimulation blocks are followed by a control condition to allow for the HRF to return to baseline. These periods are usually filled with silence or some kind of unrelated stimulation during the rest period to reduce movement artefacts and keep participants attentive to the experiment (11).

The general benefit of a block design is reflected in the robustness of the obtained hemodynamic signal. Due to repetitive presentation of a stimulus condition within a block, the captured HRF of the entire block is acquired as a superposition of the individual HRFs to each stimulus presentation. However, this design also has its shortcomings. The effects of individual stimuli within a block cannot be obtained (e.g. different responses to different words within sentences). Further, due to relatively long blocks of stimulation, the obtained responses might be influenced by effects of arousal, selective attention, or other cognitive effects that may vary between blocks and hence confound the actual effect of interest.

As an alternative to the block design, an event-related design $(37,52,53)$ can overcome these attention- or task-related effects. In this case, relatively short stimuli (1-4 s) are presented in much faster succession than the different blocks in a block paradigm. Faster stimulation reduces data acquisition time and hence the total number of epochs (events) can be increased compared to the block design. For the design of the experiment, it is important to consider that the time between two successive stimuli can be short, but should be long enough to allow the HRF to partially return to baseline in order to avoid saturation of the hemodynamic signal. Jittering the inter-stimulus interval may also contribute to reducing random physiological noise in the data. However, due to overlapping HRFs, statistical analysis of the data requires more sophisticated approaches than does a block paradigm (e.g. a general linear model (GLM), see (54); for a review, see (55)).

\section{Modulating the hemodynamic response by exper- imental variations}

\section{Stimulus-specific and area-specific activations}

While NIRS may be considered a reliable and valid tool to study stimulus-driven, bottom-up visual processing (56), clear evidence that NIRS reflects stimulus-specific and modality-specific activations to acoustic stimuli still needs to be established. The lack of clear evidence is partially due to the use of only a limited number of optodes, and hence a priori areas of interest, but also to a lack of systematic experimental designs that target modality and stimulus specificity. The first limitation is overcome by using multi-channel fNIRS that allows spatial brain mapping. It has been shown that maximal hemodynamic changes are indeed measured when channels are centered on the auditory cortex, whereas the optical signal diminishes or disappears for locations away from auditory cortex $(30,43,57,58)$. This regional specificity of activations is further supported by studies which have demonstrated differential activations at the expected occipital (V1), auditory (A1), and sensorimotor cortical regions for visual stimuli (e.g. checkerboard stimulation), motor tasks (e.g. finger-tapping), and auditory stimulation (tones), respectively $(43,59)$. More specifically, a recent study by Chen et al. (59), which measured auditory and visual areas in response to stimuli of both modalities, appeared capable of dissociating auditory from visual activations by showing maximal responses in the associated modality-specific areas. Prior to this certainly necessary systematic experiment, several prior studies had already demonstrated that the hemodynamic response to auditory stimuli can be altered by varying basic, as well as higher level, sound characteristics (bottom-up effects), and also by including top-down task characteristics within the same modality.

\section{Acoustic stimulus driven effects on the hemodynam- ic response}

Loudness modulation. Most studies performed with fMRI have demonstrated that the auditory hemodynamic response is sensitive to variations in sound level $(60,61)$. Some authors have indicated a positive, nearly linear relationship between the strength of the BOLD signal and sound intensity (62). It appears that auditory cortical responses measured with fNIRS show such a linear relationship for perceived loudness, rather than for the (physical) intensity of the sound (59). This potential discrepancy between intensity vs. loudness might suggest that fNIRS does not primarily target primary auditory cortex, where intensity effects seem more clear, but mainly relate to activity generated in secondary auditory areas (see discussion in (59); also on fMRI $(63,64))$.

Presentation and repetition rate modulation. A difference between block and event-related designs is the interval between consecutive stimuli, which is longer for a block design (3-25 s) and relatively short in an event-related design (1-4 s). When experiments discuss the interval between two stimuli, a clear distinction needs to be made as to whether one is referring to the inter-stimulus interval (ISI) between consecutive stimuli (usually referred to as the presentation rate) or to the inter-stimulus interval between identical stimuli (called the repetition rate). Generally, most studies indicate a nonlinear, inverse relationship between the cortical response and the stimulus presentation rate. As stimuli are presented in fast succession, the cortical response reaches a plateau and may even decrease (evidence from fMRI, (24,65-68); see also section on the temporal characteristics above). With fNIRS, the effect of sound presentation rate on cortical activation has been investigated by Weiss et al. (69). These authors systematically looked at presentation rates of trains 
of noise bursts at 2, 10, and $35 \mathrm{~Hz}$. The study confirmed an inverse relationship between $\mathrm{HbR}$ concentration change and presentation rate.

In addition, there is the phenomenon of stimulus-specific neural adaptation (for a review see (70)), which holds that responses to an immediately following stimulus (i.e., at short ISI) can be influenced by the response to an immediately preceding stimulus. The size of the response will be reduced if specific stimulus characteristics are repeated. That is why it is useful to distinguish the presentation rate (which concerns different stimuli) and the repetition rate (which refers to identical stimuli). If sufficient time has elapsed before the same stimulus is repeated, suppression of the hemodynamic response to the latter may be absent.

A nice illustration of this phenomenon is the oddball paradigm' (see e.g. (52). In a standard oddball paradigm, the subject is presented with a series of repetitive or 'standard' stimuli that are randomly and infrequently replaced with a distinctly different or 'deviant' stimulus. When an identical stimulus (usually called the standard stimulus) is presented several times, the neural system will adapt, leading to reduced neuronal activity for the consecutive stimuli. As a result, the hemodynamic response may saturate (71). This has been shown by Kennan et al. (52), who used a classical auditory oddball design. In the same way, continuous tones do not produce an ongoing hemodynamic response. However, their study also showed that even if the presentation rate is quite high and hence the ISI is short $(1.5 \mathrm{~s})$, a low repetition rate of the rare stimuli (which deviate from the repeated standard stimulus) can result in clear responses to these stimuli, even when presented within generally fast sequences of other stimuli. By observing these responses, it makes the technique suitable for experiments which do not last long (e.g. for children).

Stimulus complexity and impact of higher order stimulus categories. Based on FMRI, PET, and animal studies, it can be hypothesized that acoustic complexity can modulate hemodynamic responses. Simple acoustic stimuli (e.g., pure tones) primarily activate the core of the primary auditory cortex, whereas spectrally more complex sounds (e.g., complex noise, vocalizations, music, speech) also activate the surrounding higher order areas (e.g. $(72,73)$; for a review see (74)). So far, only one study used both simple tones and more complex frequency-modulated sounds within the same fNIRS study (59).

Besides acoustically driven effects, some research groups have also investigated whether fNIRS shows sensitivity to higher order stimulus features. For example, Pollonini et al. [34] varied intelligibility of auditory stimuli using sounds with otherwise comparable acoustic features (frequency content, spectro-temporal modulations, intensity). They showed that meaningful and intelligible auditory inputs led to a broader area of activation within temporal cortices. The activation decreased for distorted sounds or for non-speech environmental sounds. Bembich et al. reported fNIRS activation only for meaningful words, when compared to meaningless vowel-consonantvowel syllables (36). Further, several studies by Minagawa-Kwai et al. $(30,57,58)$ suggested that fNIRS is sensitive to language-specific speech contrasts. They demonstrated that there were left hemispheric hemoglobin changes to phoneme contrasts within the listener's native language that was not present for phoneme contrasts measured in non-native listeners. This left side functional lateralization seems to be driven by the phonemic contrast of the speech, since Sato and colleagues (42) demonstrated that a prosodic contrast led to right-sided dominance.

That the emotional valence of non-speech sounds can also yield differences in hemoglobin changes has been shown by Plichta et al. (43), who reported that both pleasant and unpleasant sounds led to significantly enhanced hemoglobin changes in auditory cortex when compared to neutral sounds. Another group looked into the effects of fear and disgust (75), and showed that sounds that were associated with fear elicited increased hemoglobin changes within temporal-parietal regions, while disgusting sounds elicited smaller changes. Taken together, these findings underscore that internal representations such as language-specific experiences, and emotional or motivational relevance, can lead to hemoglobin changes that are measurable with fNIRS.

\section{Top-down effects on the hemodynamic response}

As described above, auditory cortical responses measured with fNIRS depend on many stimulus-driven factors such as presentation rate, loudness, complexity, intelligibility, experience, and emotional valence. Only a few studies have systematically looked into the effects and response dependencies of attention and task-demands, although it has been suggested by other recording methods that the attentional focus can influence auditory cortical responses (for a meta-analysis on fMRI data see e.g. (76); for a general review see (77)). Often, fNIRS studies do not really control for attentional effects and simply require the subject to listen without giving a certain response $(11,28,75,78)$. A notable exception is the fNIRS study of Kojima and Suzuki (79), which utilized visual stimuli to show that hemodynamic responses in visual cortex are enhanced when participants are asked to perform a visual search task (compared to the inattentional condition).

For auditory stimulation the fNIRS study of Remijn and Kojima (80) assessed auditory-cortical responses within a streaming paradigm. Their results showed that performing a task of actively judging a perceived acoustic rhythm caused significantly larger $\mathrm{HbO}_{2}$ responses compared to the passive listening condition. In summary, several studies suggest that hemodynamic responses driven by auditory stimulation can be enhanced through auditory attentional engagement.

\section{Reproducibility of fNIRS measurements}

A potential advantage of the NIRS technique, compared to other neuroimaging methods, is that the brain activity of patients wearing hearing aids or implants, and also of children, may be measured in a clinical setting. However, a prerequisite for using the technique is to assess its general reproducibility or retest reliability. To our knowledge, no study has formally evaluated the reproducibility of different aspects (size, location, amplitude, temporal behaviour) of hemodynamic responses elicited by auditory stimulation. For other modalities, some multichannel 
fNIRS studies have been carried out to evaluate retest reliability (in the motor cortex, see $(39,81)$; in the occipital cortex to visual stimulation, see (53)) and they suggest that reliability at the group level exists.

So far, two studies have looked at the reliability of cortical activation in an event-related design $(53,81)$, while Sato et al. (39) has looked into data reproducibility using a block design. The authors demonstrated that absolute signal amplitudes may vary between sessions, but that the time courses of the signal are highly correlated between sessions $(r>0.8)$. To address the level of reproducibility of fNIRS in occipital cortex, Plichta et al. (53) presented periodic checkerboard stimuli and measured them at a retest interval of 3 weeks, focusing on three different aspects. First, the reproducibility of a number of activated channels over the two sessions was moderate. Second, in a single channel comparison the reproducibility was generally low, but this improved when channels were clustered (significant activations at first and second session). As a last step, they looked at topographic map activation ( $t$-values) within their pre-defined region of interest, and this showed that the fNIRS group activation maps were highly reproducible.

These outcomes show that, on a group level, fNIRS is reliable and trustworthy for fundamental research looking into effects on subjects. However, at this point, reproducibility in single subjects seems to be lacking (53,81-83). Different causes may underlie this problem. As mentioned before, often only a very limited set of fNIRS optodes is measured, and even if the researcher increases their number, makes exact and reliable positioning, uses data-driven channel selection, and analyses signals over broader areas of interest, these refinements do not always reduce between- and within-subject variance. Some authors suggest implementing MRI-guided techniques (84) to improve within-subject reliability. However, since fNIRS is intended to be used on subjects for whom fMRI scans are to be avoided (children, auditory research, participants with bionic devices), the alignment of fNIRS outcomes with structural and/or functional MRI scans is not an ideal solution.

\section{Conclusions}

This review has aimed to summarize the state of the art of how fNIRS can be used to study auditory central processing. This review indicates that increasing numbers of auditory neuroscience researchers are now readily using fNIRS to measure hemodynamic responses to a range of experimental stimuli and response conditions. Yet, despite the promising results of fNIRS, developing an ideal and stable setup and experimental design for adequate hypothesis testing still remains a challenge. By incorporating some of the aspects reviewed here - for example, details of how the cortical hemodynamic response to acoustic stimuli is modulated by stimulus presentation and repetition rates, sound duration, sound level, and attention - one might be able to acquire reliable and valid fNIRS data.

For further details on the underlying physiological principles $(85,86)$, available analysis methods, and technological advancements in fNIRS (aspects which lie outside the scope of this review), we suggest reading existing reviews $(2,3,55)$.

An important asset of fNIRS is that it can be readily combined with other neuroimaging modalities such as fMRI, EEG, PET, and MEG. Evidence comes from the increasing number of publications on multimodal imaging systems $(28,37,52,87,88)$.

FNIRS is becoming increasingly recognised as a powerful neuroimaging tool to reveal cortical activity in different patient groups of all ages. Typically, this neuroimaging method is silent and non-invasive, as opposed to fMRI and PET respectively. Furthermore, the technique is not impeded by electromagnetic bionic devices, such as a cochlear implant (CI). Anderson et al. (12) has recently shown the potential importance of applying fNIRS for longitudinal studies of cortical auditory function in CI users, giving insights into the correlation between audio-visual interactions and cortical reorganization, before and after cochlear implantation. Their results provide evidence of cortical plasticity within the bilateral superior temporal cortex (STC), suggesting how these effects may potentially explain the considerable variability in CI outcome measures.

\section{List of abbreviations}

BOLD blood oxygenation level dependent

CI cochlear implant

DOT diffuse optical tomography/topography

fNIRS functional near-infrared spectroscopy

fMRI functional magnetic resonance imaging

GLM general linear model

$\mathrm{HbO}_{2}$ oxygenated haemoglobin

HbR deoxygenated haemoglobin

HRF hemodynamic response function

ISI inter-stimulus interval

MEG magneto-encephalography

MR magnetic resonance

MRI magnetic resonance imaging

NIRI near-infrared imaging

NIRS near-infrared spectroscopy

PET positron emission tomography

RCS reference channel subtraction

STC superior temporal cortex

\section{References}

1. Jobsis F. Noninvasive, infrared monitoring of cerebral and myocardial oxygen sufficiency and circulatory parameters. Science, 1977; 198(4323): 1264-7.
2. Lloyd-Fox S, Blasi A, Elwell CE. Illuminating the developing brain: the past, present and future of functional near infrared spectroscopy. Neurosci Biobehav Rev, 2010; 34(3): 269-84. 
3. Scholkmann F, Kleiser S, Metz AJ, Zimmermann R, Mata Pavia J, Wolf $\mathrm{U}$, et al. A review on continuous wave functional nearinfrared spectroscopy and imaging instrumentation and methodology. Neuroimage, 2014; 85: 6-27.

4. Strangman G, Boas DA, Sutton JP. Non-invasive neuroimaging using near-infrared light. Biol Psychiatry, 2002; 52(7): 679-93.

5. Logothetis NK, Wandell BA. Interpreting the BOLD signal. Annu Rev Physiol, 2004; 66: 735-69.

6. Cope M, Delpy DT. System for long-term measurement of cerebral blood and tissue oxygenation on newborn infants by near infra-red transillumination. Med Biol Eng Comput, 1988; 26(3): 289-94.

7. Bortfeld H, Wruck E, Boas DA. Assessing infants' cortical response to speech using near-infrared spectroscopy. Neuroimage, 2007; 34(1): 407-15.

8. Dewey RS, Hartley DEH. Cortical cross-modal plasticity following deafness measured using functional near-infrared spectroscopy. Hear Res, 2015; 325: 55-63.

9. Johnsrude IS, Giraud AL, Frackowiak RSJ. Functional Imaging of the auditory system: the use of positron emission tomography. Audiol Neuro-otol, 2002; 7(5): 251-76.

10. Hall DA, Haggard MP, Akeroyd MA, Summerfield AQ, Palmer AR, Elliott MR, et al. Modulation and task effects in auditory processing measured using fMRI. Hum Brain Mapp, 2000; 10(3): 107-19.

11. Sevy ABG, Bortfeld H, Huppert TJ, Beauchamp MS, Tonini RE, Oghalai JS. Neuroimaging with near-infrared spectroscopy demonstrates speech-evoked activity in the auditory cortex of deaf children following cochlear implantation. Hear Res, 2010; 270(12): 39-47.

12. Anderson CA, Lazard DS, Hartley DEH. Plasticity in bilateral superior temporal cortex: effects of deafness and cochlear implantation on auditory and visual speech processing. Hear Res, 2017; 343: $138-49$.

13. Villringer A, Dirnagl U. Coupling of brain activity and cerebral blood flow: basis of functional neuroimaging. Cerebrovasc Brain Metab Rev, 1995; 7(3): 240-76.

14. Boden S, Obrig H, Köhncke C, Benav H, Koch SP, Steinbrink J. The oxygenation response to functional stimulation: is there a physiological meaning to the lag between parameters? Neuroimage, 2007; 36(1): 100-7.

15. Obrig H, Wenzel R, Kohl M, Horst S, Wobst P, Steinbrink J, et al. Near-infrared spectroscopy: does it function in functional activation studies of the adult brain? Int J Psychophysiol, 2000; 35(23): $125-42$

16. Steinbrink J, Villringer A, Kempf F, Haux D, Boden S, Obrig H. Illuminating the BOLD signal: combined fMRI-fNIRS studies. Magn Reson Imaging, 2006; 24(4): 495-505.

17. Hillman EMC. Coupling mechanism and significance of the BOLD signal: a status report. Annu Rev Neurosci, 2014; 37(1): 161-81.

18. Toronov VY, Zhang X, Webb AG. A spatial and temporal comparison of hemodynamic signals measured using optical and functional magnetic resonance imaging during activation in the human primary visual cortex. Neuroimage, 2007; 34(3): $1136-48$.

19. Jones M, Berwick J, Johnston D, Mayhew J. Concurrent optical imaging spectroscopy and laser-doppler flowmetry: the relationship between blood flow, oxygenation, and volume in rodent barrel cortex. Neuroimage, 2001; 13(6 Pt 1): 1002-15.

20. Buxton RB, Uludağ K, Dubowitz DJ, Liu TT. Modeling the hemodynamic response to brain activation. Neuroimage, 2004; 23 Suppl 1: S220-33.
21. Horner AJ, Andrews TJ. Linearity of the fMRI response in category-selective regions of human visual cortex. Hum Brain Mapp, 2009; 30(8): 2628-40.

22. Friston KJ, Fletcher P, Josephs O, Holmes A, Rugg MD, Turner R. Event-related fMRI: characterizing differential responses. Neuroimage, 1998; 7(1): 30-40.

23. Soltysik DA, Peck KK, White KD, Crosson B, Briggs RW. Comparison of hemodynamic response nonlinearity across primary cortical areas. Neuroimage. 2004;22(3):1117-27.

24. Rees G, Howseman A, Josephs O, Frith CD, Friston KJ, Frackowiak RS, et al. Characterizing the relationship between BOLD contrast and regional cerebral blood flow measurements by varying the stimulus presentation rate. Neuroimage, 1997; 6(4): 270-8.

25. Binder JR, Rao SM, Hammeke TA, Frost JA, Bandettini PA, Hyde JS. Effects of stimulus rate on signal response during functional magnetic resonance imaging of auditory cortex. Brain Res Cogn Brain Res, 1994; 2(1): 31-8.

26. Pérez-González D, Malmierca MS. Adaptation in the auditory system: an overview. Front Integr Neurosci, 2014; 8(5): 19.

27. van de Rijt LPH, van Opstal AJ, Mylanus EAM, Straatman LV, Hu HY, Snik AFM, et al. Temporal cortex activation to audiovisual speech in normal-hearing and cochlear implant users measured with functional near-infrared spectroscopy. Front Hum Neurosci, 2016; 10: 48.

28. Ohnishi M, Kusakawa N, Masaki S, Honda K, Hayashi N, Shimada Y, et al. Measurement of hemodynamics of auditory cortex using magnetoencephalography and near infrared spectroscopy. Acta Otolaryngol Suppl, 1997; 532: 129-31.

29. Minagawa-Kawai Y, Mori K, Naoi N, Kojima S. Neural attunement processes in infants during the acquisition of a languagespecific phonemic contrast. J Neurosci, 2007; 27(2): 315-21.

30. Minagawa-Kawai Y, Mori K, Sato Y, Koizumi T. Differential cortical responses in second language learners to different vowel contrasts. Neuroreport. 2004; 15(5): 899-903.

31. Sato Y, Utsugi A, Yamane N, Koizumi M, Mazuka R. Dialectal differences in hemispheric specialization for Japanese lexical pitch accent. Brain Lang, 2013; 127(3): 475-83.

32. Yoo S, Lee K-M. Articulation-based sound perception in verbal repetition: a functional NIRS study. Front Hum Neurosci, 2013;7(Sept): 540.

33. Pollonini L, Olds C, Abaya H, Bortfeld H, Beauchamp MS, Oghalai JS. Auditory cortex activation to natural speech and simulated cochlear implant speech measured with functional near-infrared spectroscopy. Hear Res, 2014; 309: 84-93.

34. Olds C, Pollonini L, Abaya H, Larky J, Loy M, Bortfeld H, et al. Cortical activation patterns correlate with speech understanding after cochlear implantation. Ear Hear, 2015; 37(3): 1-13.

35. Abla D, Okanoya K. Statistical segmentation of tone sequences activates the left inferior frontal cortex: a near-infrared spectroscopy study. Neuropsychologia, 2008; 46(11): 2787-95.

36. Bembich S, Demarini S, Clarici A, Massaccesi S, Grasso DL. Noninvasive assessment of hemispheric language dominance by optical topography during a brief passive listening test: a pilot study. Med Sci Monit, 2011; 17(12): CR692-7.

37. Ehlis AC, Ringel TM, Plichta MM, Richter MM, Herrmann MJ, Fallgatter AJ. Cortical correlates of auditory sensory gating: a simultaneous near-infrared spectroscopy event-related potential study. Neuroscience, 2009; 159(3): 1032-43.

38. Okamoto M, Dan H, Sakamoto K, Takeo K, Shimizu K, Kohno $\mathrm{S}$, et al. Three-dimensional probabilistic anatomical cranio-cerebral correlation via the international 10-20 system oriented for transcranial functional brain mapping. Neuroimage, 2004; 21(1): 99-111. 
39. Sato H, Kiguchi M, Maki A, Fuchino Y, Obata A, Yoro T, et al. Within-subject reproducibility of near-infrared spectroscopy signals in sensorimotor activation after 6 months. J Biomed Opt, 2006; 11(1): 014021.

40. Noguchi Y, Takeuchi T, Sakai KL. Lateralized activation in the inferior frontal cortex during syntactic processing: eventrelated optical topography study. Hum Brain Mapp, 2002; 17(2): 89-99. Available from: http://www.ncbi.nlm.nih.gov/ pubmed/12353243

41. Sato H, Takeuchi T, Sakai KL. Temporal cortex activation during speech recognition: an optical topography study. Cognition, 1999; 73(3): B55-66.

42. Sato Y, Mori K, Koizumi T, Minagawa-Kawai Y, Tanaka A, Ozawa E, et al. Functional lateralization of speech processing in adults and children who stutter. Front Psychol, 2011; 2(Apr): 70.

43. Plichta MM, Gerdes ABM, Alpers GW, Harnisch W, Brill S, Wieser MJ, et al. Auditory cortex activation is modulated by emotion: a functional near-infrared spectroscopy (fNIRS) study. Neuroimage, 2011; 55(3): 1200-7.

44. Zhang Q, Strangman GE, Ganis G. Adaptive filtering to reduce global interference in non-invasive NIRS measures of brain activation: how well and when does it work? Neuroimage, 2009; 45(3): 788-94.

45. Gagnon L, Perdue K, Greve DN, Goldenholz D, Kaskhedikar G, Boas DA. Improved recovery of the hemodynamic response in diffuse optical imaging using short optode separations and statespace modeling. Neuroimage, 2011; 56(3): 1362-71.

46. Zee P van der, Arridge SR, Cope M, Delphy DT. The effect of optode positioning on optical pathlength in near infrared spectroscopy of brain. Adv Exp Med Biol, 1990; 277: 79-84.

47. Okada E, Firbank M, Schweiger M, Arridge SR, Cope M, Delpy DT. Theoretical and experimental investigation of near-infrared light propagation in a model of the adult head. Appl Opt, 1997; 36(1): 21-31.

48. Cui X, Bray S, Bryant DM, Glover GH, Reiss AL. A quantitative comparison of NIRS and fMRI across multiple cognitive tasks. Neuroimage, 2011; 54(4): 2808-21.

49. Strait M, Scheutz M. What we can and cannot (yet) do with functional near infrared spectroscopy. Front Neurosci, 2014; 8(May): 117.

50. Scarpa F, Brigadoi S, Cutini S, Scatturin P, Zorzi M, Dell'acqua $\mathrm{R}$, et al. A reference-channel based methodology to improve estimation of event-related hemodynamic response from fNIRS measurements. Neuroimage, 2013; 72: 106-19.

51. Fekete T, Rubin D, Carlson JM, Mujica-Parodi LR. The NIRS analysis package: noise reduction and statistical inference. PLOS One, 2011; 6(9): e24322.

52. Kennan RP, Horovitz SG, Maki A, Yamashita Y, Koizumi H, Gore JC. Simultaneous recording of event-related auditory oddball response using transcranial near infrared optical topography and surface EEG. Neuroimage, 2002; 16(3): 587-92.

53. Plichta MM, Herrmann MJ, Baehne CG, Ehlis AC, Richter MM, Pauli $P$, et al. Event-related functional near-infrared spectroscopy (fNIRS): are the measurements reliable? Neuroimage, 2006; 31(1): 116-24.

54. Plichta MM, Heinzel S, Ehlis AC, Pauli P, Fallgatter AJ. Model-based analysis of rapid event-related functional near-infrared spectroscopy (NIRS) data: a parametric validation study. Neuroimage, 2007; 35(2): 625-34.

55. Tak S, Ye JC. Statistical analysis of fNIRS data: a comprehensive review. Neuroimage, 2014; 85 (Pt 1): 72-91.
56. Plichta MM, Herrmann MJ, Ehlis AC, Baehne CG, Richter MM, Fallgatter AJ. Event-related visual versus blocked motor task: detection of specific cortical activation patterns with functional near-infrared spectroscopy. Neuropsychobiol, 2006; 53(2): 77-82.

57. Minagawa-Kawai Y, Mori K, Furuya I, Hayashi R, Sato Y. Assessing cerebral representations of short and long vowel categories by NIRS. Neuroreport, 2002; 13(5): 581-4.

58. Minagawa-Kawai Y, Mori K, Sato Y. Different brain strategies underlie the categorical perception of foreign and native phonemes. J Cogn Neurosci, 2005; 17(9): 1376-85.

59. Chen L-C, Sandmann P, Thorne JD, Herrmann CS, Debener S. Association of concurrent fNIRS and EEG signatures in response to auditory and visual stimuli. Brain Topogr, 2015; 28(5): 710-25.

60. Jäncke L, Shah NJ, Posse S, Grosse-Ryuken M, Müller-Gärtner HW. Intensity coding of auditory stimuli: an fMRI study. Neuropsychologia, 1998; 36(9): 875-83.

61. Lockwood AH, Salvi RJ, Coad M Lou, Arnold SA, Wack DS, Murphy BW, et al. The functional anatomy of the normal human auditory system: responses to 0.5 and $4.0 \mathrm{kHz}$ tones at varied intensities. Cereb Cortex, 1999; 9(1): 65-76.

62. Uppenkamp S, Röhl M. Human auditory neuroimaging of intensity and loudness. Hear Res, 2014; 307: 65-73.

63. Langers DRM, Backes WH, van Dijk P. Representation of lateralization and tonotopy in primary versus secondary human auditory cortex. Neuroimage, 2007; 34(1): 264-73.

64. Röhl M, Uppenkamp S. Neural coding of sound intensity and loudness in the human auditory system. JARO, 2012; 13(3): 369-79.

65. Rinne T, Pekkola J, Degerman A, Autti T, Jääskeläinen IP, Sams $\mathrm{M}$, et al. Modulation of auditory cortex activation by sound presentation rate and attention. Hum Brain Mapp, 2005; 26(2): 94-9.

66. Sheth SA, Nemoto M, Guiou M, Walker M, Pouratian N, Toga AW. Linear and nonlinear relationships between neuronal activity, oxygen metabolism, and hemodynamic responses. Neuron, 2004; 42(2): 347-55.

67. Harms MP, Melcher JR. Sound repetition rate in the human auditory pathway: representations in the waveshape and amplitude of fMRI activation. J Neurophysiol, 2002; 88(3): 1433-50.

68. Tanaka H, Fujita N, Watanabe Y, Hirabuki N, Takanashi M, Oshiro Y, et al. Effects of stimulus rate on the auditory cortex using fMRI with "sparse" temporal sampling. Neuroreport, 2000; 11(9): 2045-9.

69. Weiss AP, Duff M, Roffman JL, Rauch SL, Strangman GE. Auditory stimulus repetition effects on cortical hemoglobin oxygenation: a near-infrared spectroscopy investigation. Neuroreport, 2008; 19(2): 161-5.

70. Grill-Spector K, Henson R, Martin A. Repetition and the brain: neural models of stimulus-specific effects. Trends Cogn Sci, 2006; 10(1): 14-23

71. Nelken I. Stimulus-specific adaptation and deviance detection in the auditory system: experiments and models. Biol Cybern, 2014; 108(5): 655-63.

72. Hall DA, Johnsrude IS, Haggard MP, Palmer AR, Akeroyd MA, Summerfield AQ. Spectral and temporal processing in human auditory cortex. Cereb Cortex, 2002; 12(2): 140-9.

73. Strainer JC, Ulmer JL, Yetkin FZ, Haughton VM, Daniels DL, Millen SJ. Functional MR of the primary auditory cortex: an analysis of pure tone activation and tone discrimination. Am J Neuroradiol, 1997; 18(4): 601-10. 
74. Samson F, Zeffiro TA, Toussaint A, Belin P. Stimulus complexity and categorical effects in human auditory cortex: an activation likelihood estimation meta-analysis. Front Psychol, 2010; 1(Jan): 241.

75. Köchel A, Schöngassner F, Schienle A. Cortical activation during auditory elicitation of fear and disgust: a near-infrared spectroscopy (NIRS) study. Neurosci Lett, 2013; 549: 197-200.

77. Alho K, Rinne T, Herron TJ, Woods DL. Stimulus-dependent activations and attention-related modulations in the auditory cortex: a meta-analysis of fMRI studies. Hear Res, 2014; 307: 29-41.

77. Lee AKC, Larson E, Maddox RK, Shinn-Cunningham BG. Using neuroimaging to understand the cortical mechanisms of auditory selective attention. Hear Res, 2014; 307: 111-20.

78. Santosa H, Hong MJ, Hong K-S. Lateralization of music processing with noises in the auditory cortex: an fNIRS study. Front Behav Neurosci, 2014; 8(Dec): 418

79. Kojima H, Suzuki T. Hemodynamic change in occipital lobe during visual search: visual attention allocation measured with NIRS. Neuropsychologia, 2010; 48(1): 349-52.

80. Remijn GB, Kojima H. Active versus passive listening to auditory streaming stimuli: a near-infrared spectroscopy study. J Biomed Opt, 2010; 15(3): 037006.

81. Plichta MM, Herrmann MJ, Baehne CG, Ehlis AC, Richter MM, Pauli P, et al. Event-related functional near-infrared spectroscopy (fNIRS) based on craniocerebral correlations: reproducibility of activation? Hum Brain Mapp, 2007; 28(8): 79-18.
82. Kono T, Matsuo K, Tsunashima K, Kasai K, Takizawa R, Rogers $\mathrm{MA}$, et al. Multiple-time replicability of near-infrared spectroscopy recording during prefrontal activation task in healthy men. Neurosci Res, 2007; 57(4): 504-12.

83. Schecklmann M, Ehlis AC, Plichta MM, Fallgatter AJ. Functional near-infrared spectroscopy: a long-term reliable tool for measuring brain activity during verbal fluency. Neuroimage, 2008; 43(1): 147-55.

83. Boas DA, Dale AM, Franceschini MA. Diffuse optical imaging of brain activation: approaches to optimizing image sensitivity, resolution, and accuracy. Neuroimage, 2004; 23(Supp 1): S275-88.

85. Jacques SL. Optical properties of biological tissues: a review. Phys Med Biol, 2013; 58: R37.

86. Durduran T, Choe R, Baker WB, Yodh AG. Diffuse optics for tissue monitoring and tomography. Rep Prog Phys, 2010; 73: 43.

87. Mehagnoul-Schipper DJ, van der Kallen BFW, Colier WNJM, van der Sluijs MC, van Erning LJTO, Thijssen HOM, et al. Simultaneous measurements of cerebral oxygenation changes during brain activation by near-infrared spectroscopy and functional magnetic resonance imaging in healthy young and elderly subjects. Hum Brain Mapp, 2002; 16(1): 14-23.

88. Wallois F, Mahmoudzadeh M, Patil A, Grebe R. Usefulness of simultaneous EEG-NIRS recording in language studies. Brain Lang, 2012; 121(2): 110-23. 